\title{
Implementing Health Care Technology Research into Practice to Improve Adult Asthma Management
}

\author{
Peter J. Cvietusa, MD¹, Glenn K. Goodrich, MS $^{2}$, Jo Ann Shoup, PhD², David A. Steffen, \\ $\mathrm{MPH}^{2}$, Cathy Tacinas, $\mathbf{R N}^{1}$, Nicole M. Wagner, $\mathbf{M P H}^{2}$, Courtney B. Anderson, $\mathbf{M P H}^{2}$, Debra \\ P. Ritzwoller, $\mathbf{P h D}^{2}$, and Bruce G. Bender, $\mathrm{PhD}^{3}$ \\ ${ }^{1}$ Department of Asthma, Allergy and Immunology, Kaiser Permanente Colorado, Denver, CO \\ ${ }^{2}$ Institute for Health Research, Kaiser Permanente Colorado, Aurora, CO \\ ${ }^{3}$ Department of Pediatrics, National Jewish Health, Denver, CO
}

\begin{abstract}
BACKGROUND: Use of health technology has shown potential to improve asthma adherence and outcomes.Few studies have looked at the implementation of such research within larger asthma populations.
\end{abstract}

OBJECTIVE: This report examines the process of translating results from a pragmatic trial using speech recognition (SR) in children with persistent asthma into standard operating procedure within a large health maintenance organization. Medication adherence and outcomes in adults with asthma were examined.

METHODS: The SR protocol was implemented for the total Kaiser Permanente Colorado (KPCO) patient population of 480,142, of which 36,356 had asthma. Patients had persistent asthma, filled one or more inhaled corticosteroid prescriptions in the prior six months, and remained continuously enrolled with KPCO for two years. Documented exacerbations included presence of a hospitalization, emergency room visit, or course of oral steroid where asthma was the principle diagnosis. Adherence and exacerbation events were compared one-year pre and one year post intervention for 4,510 adults ages 19-64.

RESULTS: Patient adherence demonstrated a small but significant improvement from $39.5 \%$ to $41.7 \%$ ( $\mathrm{p}<0.0001$ ). Although not significant, data trends suggested greater improvement for patients with lower socioeconomic status. When an outlier month was removed from both the pre and post intervention time periods, courses of oral steroids decreased.Emergency room visits and hospitalizations were infrequent in both time periods and did not decrease over time.

Corresponding author: Peter J. Cvietusa, MD, Address: 10400 East Alameda Ave, Denver, CO 80247, Phone: (303) 239-7342, Fax: (303) 360-1278, Peter.J.Cvietusa@kp.org.

Publisher's Disclaimer: This is a PDF file of an unedited manuscript that has been accepted for publication. As a service to our customers we are providing this early version of the manuscript. The manuscript will undergo copyediting, typesetting, and review of the resulting proof before it is published in its final citable form. Please note that during the production process errors may be discovered which could affect the content, and all legal disclaimers that apply to the journal pertain.

Conflicts of Interest: The authors have no conflicts of interest to disclose. 
CONCLUSIONS: A low cost SR intervention reminding patients to fill and take their daily controller asthma medication can improve treatment adherence and decrease the need for oral steroids due to asthma exacerbations, but not decrease emergency room visits or hospitalizations.

\section{Keywords}

asthma; communication technology; Electronic Medical Record; inhaled corticosteroid; adherence

\section{Introduction}

The National Heart, Lung, and Blood Institute's (NHLBI) evidence-based guidelines for the treatment of asthma recommend that patients with persistent asthma take an asthma controller medication on a daily basis. ${ }^{1}$ Failure to do so can lead to an increased risk of severe asthma exacerbations, including hospitalizations, emergency room visits, and oral corticosteroid use. ${ }^{2}$ Despite these risks, adult and pediatric nonadherence to controller therapies ranges from $30 \%$ to $70 \%{ }^{3}$ In a review of electronic prescriptions, one study found that $24 \%$ of asthma exacerbations and $60 \%$ of asthma-related hospitalizations could be attributed to inhaled corticosteroid (ICS) nonadherence. ${ }^{4}$

Randomized controlled trials over the last 20 years have utilized a variety of techniques to increase patient adherence, without significant clinical improvements. ${ }^{5,6}$ While studies that combine several components into a single intervention can often be more effective at improving adherence with asthma medications, ${ }^{7}$ they are usually more resource intensive and thus not easily implemented in the clinical setting.Furthermore, these efficacy studies often do not reflect realworld settings. For example, efficacy interventions typically do not include patients with comorbidities or capture how daily medications are taken by patients over long periods of time.In implementation research, pragmatic or real world studies (effectiveness trials), where inclusion criteria do not exclude large numbers of patients and which typically occur in the course of routine care, are important to understanding and addressing adherence outside of research settings. ${ }^{8}$ For these reasons, in recent years the NHLBI, the National Institutes of Health, and the Patient-Centered Outcomes Research Institute have all provided extensive support for implementation research. ${ }^{8}$

A new and promising intervention pathway emerges from studies that leverage communication technology and the electronic health record (EHR) to improve adherence. Communication technology that applies automated SR telephone calls, text messaging or emails, when combined with an electronic medical record to identify eligible patients, has the potential to be utilized as a reminder system in a low cost, far-reaching intervention. In recently published results from a pragmatic trial applying SR telephone calls integrated with an EHR database, we reached out to parents of children ages 3-12 when their child's controller medication was due or overdue to engage and inform them about the importance of the child's medication for asthma control. ${ }^{9}$ The study, which included 1187 children enrolled at Kaiser Permanente Colorado (KPCO) over a 2year period, showed 25\% greater rate of adherence in the intervention group over usual guideline based care.Based on the results of that pragmatic trial, we expanded the successful intervention to reach the larger KPCO membership with persistent asthma as a component of standard operating procedures. 
In this report, we evaluate the results of the full implementation of the intervention into KPCO practices. To assist in evaluating the implementation of this prior study, we used the Consolidated Framework for Implementation Research (CFIR). Briefly, CFIR is composed of major domains that are important to effective implementation, including engagement of leadership in scalability of the intervention and assessing the compatibility of the intervention to a broader population. ${ }^{10}$ We used this model as a lens to look at the organizational level findings of the implementation of this pragmatic research study into practice.

\section{Methods}

This project was conducted at KPCO, a group-model health maintenance organization (HMO) serving the Denver-Boulder-Longmont region in Colorado. This observational review was conducted from October 2012 to October 2014. During this time, KPCO had a patient population of roughly 500,000 members, served by 18 primary care and 2 specialty care medical offices, 2 contract hospitals, and more than 800 physicians.KPCO uses a commercially available EHR (Epic) in routine care delivery. The patient population was comprised of adults ages 19-64 with the diagnosis of persistent asthma, determined by problem list diagnosis in the EHR. The age of the patient was determined using their age on the date of October 23, 2014.An age cutoff of 64 was used to reduce the number of patients who may have had Chronic Obstructive Pulmonary Disease (COPD) or Asthma/COPD overlap syndrome.Patients included were required to meet the following criteria both during the year prior to the start of the intervention and the year after the start of the intervention:a) be continuously enrolled at KPCO; b) have a diagnosis of persistent asthma and c) have filled at least one controller asthma medication.

A project database was created to allow automated exchange of information between the EHR and the speech recognition (SR) program. This information included the name of the patient, home telephone number, name of the controller medication, refill history, and the last 4 digits of the credit card of patients enrolled in the mail-order pharmacy program. The project used an internally developed SR program that was closely modeled after the one used in the initial study. ${ }^{9}$ The SR software creates computer generated telephone conversations using medical and demographic information contained in the EHR database, such as the name of the prescribed medication, to tailor each call. The program responded to patient answers to questions in the call regarding a desire for help with medication refills or a call back from an asthma care nurse.

To fully implement this intervention to the adult population, the protocol message was modified only slightly for ages 19-64. SR calls were developed in both English and Spanish. Each call lasted from 2 to 5 minutes. A flow diagram of the IVR program is shown in Figure 1. The SR program was also able to detect if the number given by the patient was text enabled (a cell phone vs landline) and to determine if the number was on a do-not-call list. A reminder call or text message was sent 5-11 days prior to when the patient was scheduled to run out of their controller medication. Content for the calls included a reminder to refill the ICS, assistance refilling the medication, an option to hear about what good asthma control should look like, and the option for further help through a callback from a pharmacy staff 
member or asthma care nurse. If the patient needed to speak with a physician, the asthma care nurse would facilitate this. When texting was used, it contained the reminder of they need to fill their medication and a phone number to call to assist with filling their medication.

When the refill was 30 days past the date when a patient was due to refill their controller medication, they received a second, "tardy" call or text. Call content was similar to the basic refill call and provided the same options. However, the tardy refill call increased emphasis on the importance of medication adherence on the patient's health. Given the results of the previous study and to off-load the work of the asthma care nurses, the decision was made to no longer have the asthma care nurse call patients who failed to respond to the two reminder SR calls, as was done in our previous study. ${ }^{9}$ Calls were randomly placed between 9 AM and $8 \mathrm{PM}$, until the patient or answering machine was reached. If the call was received by an answering machine, the SR program left a medication refill reminder message and provided a callback number. Patients could opt out of receiving the calls or text messages at any time.

\section{Study Outcomes}

Study outcomes compared both adherence rates and adverse asthma outcomes in the same patients during the year prior to the intervention and the year during the intervention. In this way, patients served as their own internal controls. Adherence was measured as a proportion of days covered (PDC) ${ }^{11}$ over the 12-month period (both the year prior and the year after the intervention was started). The PDC was calculated as the total number of controller medication days supplied over the (pre or post) year divided by 365. Calculation of the PDC was adjusted to account for the medication supply that existed before the study initiation date or if the supply extended beyond the end of the study period.

Adverse asthma outcomes included hospitalizations, emergency room visits and courses of oral steroids. All adverse outcomes were required to be linked with a primary diagnosis of asthma. These asthma exacerbations were analyzed as counts.If a patient was hospitalized after an emergency room visit, this was counted as one exacerbation.

To evaluate the significance of the pre- vs post-intervention periods, we looked at a pre-post dummy variable in regression analysis, including two records for each patient. The regressions used random effects to take into account the high correlation between records when the same person was being measured over time. For the PDC, a Poisson regression with a negative binomial distribution was used. For exacerbations, a Poisson regression was used to account for the count of exacerbations in the pre and post period. In a sub-analysis, we also looked at PDC rates and adverse outcomes in a lower vs. higher socioeconomic status (SES) population using pre-post, lower vs. higher SES, and an interaction term in a negative binomial model using random effects. SES rates were determined at the tract and block level of geography. If $20 \%$ or more of households are at $100 \%$ or below federal poverty level (function of number of family members and income) and $25 \%$ or more of adults (aged 25+) have less than high school education, patients living in this area were determined to be in a lower SES population. 
To assess how well the implementation process worked, we used the 5 domains of CFIR. These five domains and their definitions are as follows: Intervention Characteristics (key attributes that influence the success of implementation); Outer Setting (policies, incentives, patient needs); Inner Setting (includes culture, communication, readiness for implementation); Characteristics of Individuals (Actions and behaviors of individuals within networks); and Process (knowledge building about why implementation succeeds or fails). Examples of a construct from each domain were applied, and theoretical context provided a framework to identify barriers and facilitators in translating the research evidence into sustainable practice.

\section{Results}

Records of 4,510 adults, ages 19-64, with persistent asthma were compared one year prior to the start of the SR program and one year after the start of the intervention. All patients included in this analysis were required to be continuously enrolled for the total 2-year period. A total of 24,599 calls or texts were sent to the 4,510 patients during the study timeframe of October 23, 2012 to October 24, 2014. There were 782 (3.17\%) calls that did not reach the patient.Of these, 127 were on the no call/opt out list. It was not possible to determine whether or not patients had received a text message. Table 1 shows the demographics and other characteristics of the population studied. Patient adherence, defined as PDC, improved from $39.5 \%$ in the year prior to implementing the SR intervention, to $41.7 \%$ ( $\mathrm{p}<0.0001$ ) in the year following the start of the intervention. In the lower SES group, which started at a lower level of adherence, the PDC change appeared to be even greater relative to the average or high SES group ( $4.0 \%$ vs 2.2 and $2.1 \%$ respectively) but the difference was not statistically significant $(\mathrm{p}=0.1050)$ (Table 2$)$.

Hospitalization rates prior to the intervention (1.3\%) did not decrease significantly in the year after the SR intervention (1.1\%). Similarly, emergency room visits with asthma as a principle diagnosis also did not change significantly (3.3\% vs $2.9 \%$, pre- vs post-).Additionally, the number of prescriptions for oral steroids did not change ( $28.3 \%$ vs $26.2 \%$ pre- vs post-). However, it was later revealed that during the implementation year, the month of September, often a month of higher than normal rates of asthma exacerbations, ${ }^{12}$ had an atypically high number of asthma exacerbations in the Denver/Boulder area.Because these data represent a secondary analysis, we removed this month from the data set for both years. Subsequently, the overall number of prescriptions for oral steroids decreased significantly ( $\mathrm{p}=0.021)$. However, this secondary, sub-analysis did not change any of the other outcomes (Table 3).

Table 4 describes the 5 domains of CFIR and provides context for the overall success of implementing the SR system into operational practice at KPCO. CFIR was employed to identify any potential barriers to sustaining the SR system. For example, senior leadership championed the implementation of the SR reminder system to a broader population (inclusion of adults), but ongoing assessment of effectiveness was not incorporated. Instead, the research team conducted post intervention assessment and evaluation. 


\section{Discussion}

\section{Adherence and Outcomes}

This report tracks the final translational research step from implementation study to full implementation in a large healthcare system. Results show that a SR system adopted as standard operating procedure to remind patients with asthma to fill and use their controller medications improved adherence by a small but significant degree. However, the improvement in adherence was smaller than seen in our previous study ${ }^{9}$ and may not be clinically significant. There are a number of considerations that might explain this outcome.

First, this adult population already had a fairly high adherence rate, higher than the starting point for the children in our previous study $(39.5 \% \text { vs } 35.5 \%)^{9}$ and that seen in other studies. ${ }^{14-17}$ Introduction of the intervention in a more typical, low-adherence population might have had a greater impact. While not clinically significant, this was suggested in our sub-analysis looking at the impact of the intervention on a lower SES population.Next, our criteria for who received the SR intervention had few restrictions (diagnosis of persistent asthma and at least one fill of an ICS in the previous year). Outreach to such a broad population likely included patients who may not truly have persistent asthma or were overprescribed a controller inhaler, thus leading to intentional nonadherence by the patient. ${ }^{21}$ Finally, our decision to not have our asthma care nurses call those patients who were not responding to the IVR outreach may have led to less improvement in adherence but likely also led to cost savings (see below). The asthma care nurses make use of other opportunities to encourage patients to be more adherent with their controller medications, including contacting patients who have recently been to the ED for an asthma flare, outreaching to patients referred by the Primary Care providers for further asthma education, and outreaching to patients who have re-filled an albuterol inhaler within 2 months of their last fill (evidence of over-filling their albuterol). Also, in the KPCO system, all patients who have been hospitalized for asthma are referred to an allergist, offering further opportunity to improve medication adherence.

It is not surprising that the small improvement in adherence did not significantly change adverse asthma outcomes.After excluding outliers, a significant change in prednisonedefined exacerbations emerged, though this may not be clinically significant. Populationbased studies on this topic have suggested a relationship between poor adherence and poorer outcomes, ${ }^{13,23}$ but adherence intervention studies have not shown an improvement in outcomes. ${ }^{24}$ One study showed a difference in outcomes only when comparing patients with a relatively low (25\%) adherence rate, to patients with a very strong (75\%) adherence rate. ${ }^{13}$ Hence, a relatively larger improvement in medication adherence may be required to see an improvement in asthma outcomes.Better identification of patients who receive the intervention - those whose asthma is less well controlled and possibly weeding out those who have been overprescribed or inappropriately prescribed a controller inhaler - might also improve the effect of increased adherence on asthma outcomes. ${ }^{24}$ We did not make any attempt to determine barriers for nonadherence in this population prior to intervention. Integrating a simple, validated questionnaire to assess barriers to non-adherence may have helped determine who would be better served by an SR reminder to fill their controller 
medication. ${ }^{22}$ We will continue to re-evaluate the balance between utilizing technology to offload our providers and reaching out to patients when a human touch is needed.

\section{Communication technology}

As communication technology improves, further tailoring to specific sub-populations such as adolescent, elderly, and non-English speaking patients, may produce greater adherence impact. A recent study in a Medicare population, utilizing text messaging to remind patients to fill their medications, was effective and well received by the study population. ${ }^{18}$ Continuous enhancements are being made to the KPCO SR system. In future research we will be evaluating patient preference for email, text, or phone call outreach. The SR intervention has been adapted to reach Spanish-speaking members and has become standard operating practice at KPCO. That said, the Kaiser patient population is not as diverse as the general population, which was another limitation of this study.

In a post-intervention assessment and evaluation, both facilitators and barriers to implementing this technology were identified using a theory-based model (CFIR, Table 4). Facilitators included the use of technology-driven, short messages within an integrated care delivery system, involvement of clinical leaders, and support from KPCO leadership. Barriers to use included lack of patient engagement, which may be a function of type of messaging format (phone, text, email), and inaccurate information in the EHR leading to patients either not getting messages or getting poorly timed messages.

\section{Cost, scalability, and sustainability}

Due to the retrospective nature of this study, we were not able to conduct a formal costeffectiveness analysis.However, there are a number of reasons why we believe this was and will be a cost-effective intervention.Start-up costs for an SR system and personnel can be costly but the personnel used to develop this particular SR program were already in place and working on other SR interventions within KPCO, thus, reducing development costs. A proposal to build the SR internally was budgeted at $\$ 11,000$, while cost for an outside vendor to develop this system was estimated at $\$ 24,000$, making it economically favorable to operationalize the SR intervention.Moreover, based on SR costs (including multiple phone lines, programming costs, etc.) derived from a previously published KPCO based study, ${ }^{19}$ we estimate that ongoing costs of the system will not exceed $\$ 5,000$ per year.This SR intervention was effectively scaled up to reach more patients than our previous study to include the whole of the KPCO patient population, over 36,000 patients with asthma per year, and it can easily allow for membership growth in the future.Annual KPCO SR technology costs are declining, as the cost per telephone line decreases and the capacity per line increases. Altogether, this makes implementation sustainable.

Prior to the use of this SR program, asthma care nurses were routinely calling patients who had not filled their controller medications, working off lists of late-to-refill patients that were generated by the administrative databases. The SR calls were timelier than the nurses' calls and saved the asthma care nurses many hours of work by reducing the number of calls they made. By employing standard 2012 Bureau of Labor Statistics ${ }^{20}$ standard wage estimates, along with a fringe benefit rate of 0.50 , the cost of the system targeting approximately 4,500 
patients would "break-even" if the annual number of hours of work performed by nurses making reminder calls to patients were reduced by 80 . Our expectation was that this would allow the asthma care nurses to outreach to those patients where a "human touch" was most beneficial, including instances where the SR may not have changed patient behavior.

In summary, this report demonstrated that an SR reminder system was relatively easily adopted and implemented in a large HMO at a low cost, and was easy to maintain, allowing sustained reach to a greater population in an effort to improve asthma medication adherence. Further tailoring of the intervention itself and the population chosen for the intervention may not only help improve adherence but also asthma outcomes. This will be examined in future studies.

\section{Acknowledgments}

Funding source: This work was supported by the National Heart, Lung, and Blood Institute, grant number R01HL084067-05.

\section{List of Abbreviations:}

$\begin{array}{ll}\text { SR } & \text { speech recognition } \\ \text { HMO } & \text { health maintenance organization } \\ \text { KPCO } & \text { Kaiser Permanente Colorado } \\ \text { ICS } & \text { inhaled corticosteroid } \\ \text { SES } & \text { socioeconomic status } \\ \text { NHLBI } & \text { National Heart, Lung, and Blood Institute } \\ \text { EHR } & \text { electronic health record } \\ \text { CFIR } & \text { Consolidated Framework for Implementation Research } \\ \text { COPD } & \text { Chronic Obstructive Pulmonary Disease } \\ \text { PDC } & \text { proportion of days covered }\end{array}$

\section{References}

1. National Heart, Lung, and Blood Institute. National Asthma Education and Prevention Program, Expert Panel Report 3: Guidelines for the diagnosis and management of asthma, full report 2007 Bethesda, MD: National Heart, Lung \& Blood Institute; 2007.

2. Engelkes M, Janssens HM, de Jongste JC, Sturkenboom MC, Verhamme KM. Medication adherence and the risk of severe asthma exacerbations: a systematic review. Eur Respir J 2015;45:396-407. [PubMed: 25323234]

3. Eakin MN, Rand CS. Improving patient adherence with asthma self-management practices: what works? Ann Allergy Asthma Immunol 2012;109:90-2. [PubMed: 22840247]

4. Williams LK, Peterson EL, Wells K, Ahmedani BK, Kumar R, Burchard EG, et al. Quantifying the proportion of severe asthma exacerbations attributable to inhaled corticosteroid nonadherence. $\mathrm{J}$ Allergy Clin Immunol 2011;128:1185-91. [PubMed: 22019090] 
5. Lee JX, Wojtczak HA, Wachter AM, Lee ML, Burns L, Chen D, et al. Understanding asthma medical nonadherence in an adult and pediatric population. J Allergy Clin Immunol Pract 2015;3:436-7. [PubMed: 25609340]

6. Bender BG. Nonadherence to asthma treatment: getting unstuck. J Allergy Clin Immunol Pract 2016;4:849p51. [PubMed: 27587318]

7. Haynes RB, McDonald H, Garg AX, Montague P. Interventions for helping patients to follow prescriptions for medications. Cochrane Database Syst Rev 2002;(2) CD000011.

8. Apter AJ. Understanding adherence requires pragmatic trials: lessons from pediatric asthma. JAMA Pediatr 2015;169:310-11. [PubMed: 25664425]

9. Bender BG, Cvietusa PJ, Goodrich GK, Lowe R, Nuanes HA, Rand C, et al. Pragmatic trial of healthcare technologies to improve adherence to pediatric asthma treatment: a randomized clinical trial. JAMA Pediatr 2015;169:317-23. [PubMed: 25664620]

10. Damschroder LJ, Aron DC, Keith RE, Kirsh SR, Alexander JA, Lowery JC. Fostering implementation of health services research findings into practice: a consolidated framework for advancing implementation science. Implement Sci 2009;4:50. [PubMed: 19664226]

11. Andrade SE, Kahler KH, Frech F, Chan KA. Methods for evaluation of medication adherence and persistence using automated databases. Pharmacoepidemiol Drug Saf 2006;15(8):565-74. [PubMed: 16514590]

12. Sears MR, Johnston NW. Understanding the September asthma epidemic. J Allergy Clin Immunol 2007;120(3):526-9. [PubMed: 17658590]

13. Williams LK, Pladevall M, Xi H, Peterson EL, Joseph C, Lafata JE, et al. Relationship between adherence to inhaled corticosteroids and poor outcomes among adults with asthma. J Allergy Clin Immunol 2004;114(6):1288-93. [PubMed: 15577825]

14. Bender BG, Pedan A, Varasteh LT. Adherence and persistence with fluticasone propionate/ salmeterol combination therapy. J Allergy Clin Immunol 2006;118(4):899904.

15. Sloan CD, Gebretsadik T, Wu P, Mitchel EF, Hartert TV. Reactive versus proactive patterns of inhaled corticosteroid use. Ann Am Thorac Soc 2013;10(2):131-4. [PubMed: 23607842]

16. Vanelli M, Pedan A, Liu N, Hoar J, Messier D, Kiarsis K. The role of patient inexperience in medication discontinuation: a retrospective analysis of medication nonpersistence in seven chronic illnesses. Clin Ther 2009;31(11):2628-52. [PubMed: 20110007]

17. Vaidya V, Gupte R, Balkrishnan R. Failure to refill essential prescription medications for asthma among pediatric Medicaid beneficiaries with persistent asthma. Patient Prefer Adherence 2013;7:21-6. [PubMed: 23341734]

18. Brar Prayaga R, Jeong EW, Feger E, Noble HK, Kmiec M, Prayaga RS. Improving refill adherence in Medicare patients with tailored and interactive mobile text messaging: pilot study. JMIR Mhealth Uhealth 2018;6(1):e30. [PubMed: 29382623]

19. Shoup JA, Madrid C, Koehler C, Lamb C, Ellis J, Ritzwoller DP, et al. Effectiveness and cost of influenza vaccine reminders for adults with asthma or chronic obstructive pulmonary disease. Am J Manag Care 2015;21(7):e405-13. [PubMed: 26295268]

20. Bureau of Labor Statistics. Occupational employment and wages, 52012 Available from: https:// www.bls.gov/oes/tables.htm. Accessed July 18, 2018.

21. Foster JM, Usherwood T, Smith L, Sawyer SM, Xuan W, Rand CS, et al. Inhaler reminders improve adherence with controller treatment in primary care patients with asthma. J Allergy Clin Immunol 2014;134(6):1260-1268. [PubMed: 25062783]

22. Schatz M, Zeiger RS, Yang SJ, Weinstein AG, Chen W, Saris-Baglama RN, et al. Development and preliminary validation of the adult asthma adherence questionnaire ${ }^{\mathrm{TM}}$. J Allergy Clin Immunol Pract 2013;1(3):280-288. [PubMed: 24565486]

23. Suissa S, Ernst P, Benayoun S, Baltzan M, Cai B. Low-dose inhaled corticosteroids and the prevention of death from asthma. N Engl J Med 2000;343(5):332-336. [PubMed: 10922423]

24. Chan AH, Reddel HK, Apter A, Eaken M, Riekert K, Foster JM. Adherence monitoring and ehealth: how clinicians and researchers can use technology to promote inhaler adherence for asthma. J Allergy Clin Immunol Pract 2013;1(5):446-454. [PubMed: 24565615] 


\section{What is already known about this topic?}

Nonadherence to asthma medications has been well established. Interventions to improve asthma medication adherence have only been moderately successful, but the use of communication technology combined with the electronic medical record offers new hope to improve it.

\section{What does this article add to our knowledge?}

The use of communication technology and the electronic health record can be leveraged as a reminder system to improve asthma medication adherence in a large healthcare system.

\section{How does this study impact current management guidelines?}

Use of speech recognition communication technology in tandem with rich data sources such as the electronic health record has the potential to become standard care in managing population-based asthma. 
Messages are sent to each adult patient diagnosed with persistent asthma with a controller medication on file.

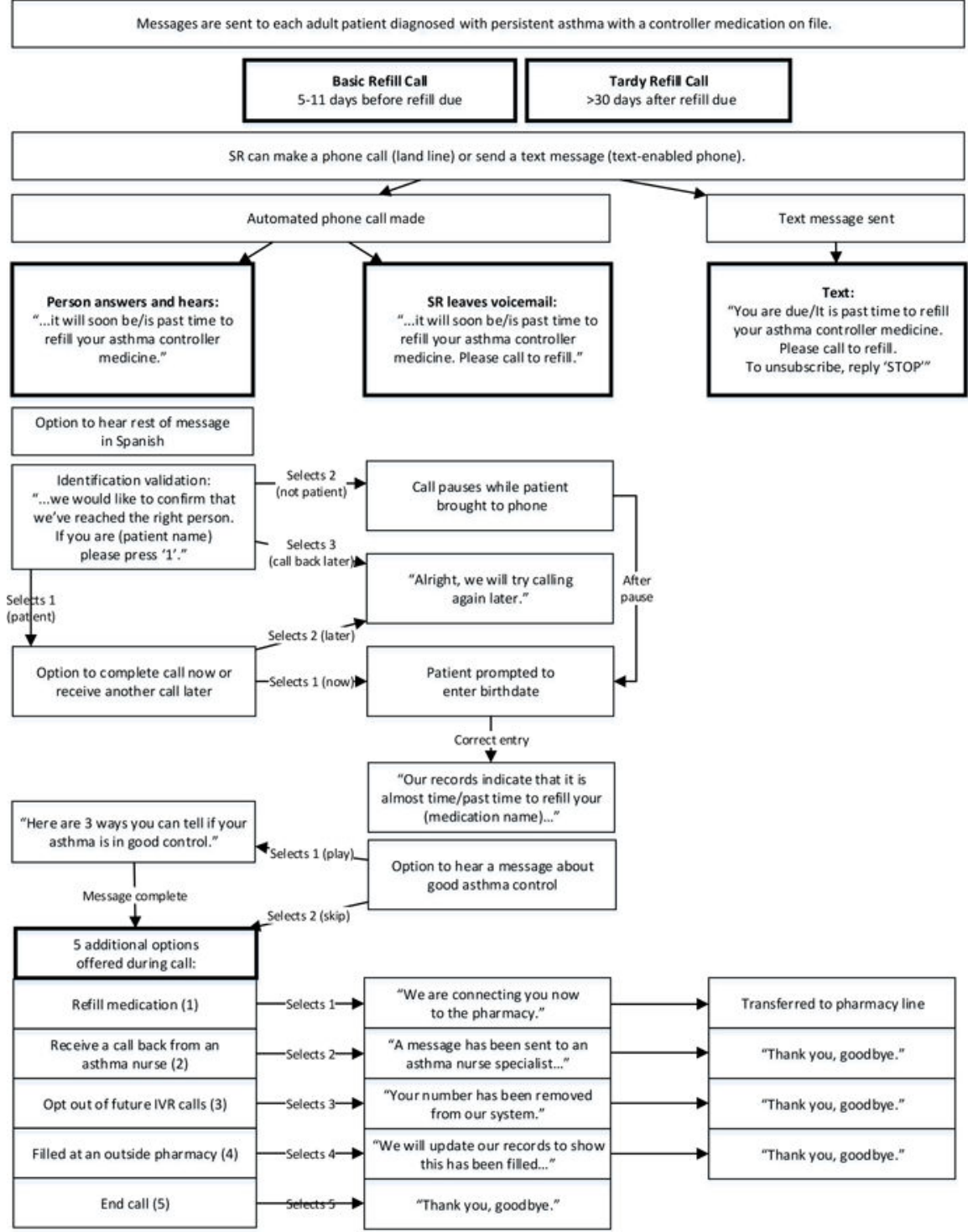

Figure 1:

Flow diagram of speech recognition (SR) medication refill reminder process. 
Table 1:

Baseline characteristics of the study cohort $(\mathrm{N}=4510)$

\begin{tabular}{ll}
\hline Characteristic & $\boldsymbol{N}(\boldsymbol{\%})$ \\
Gender & \\
Male & $1726(38.27)$ \\
Female & $2784(61.73)$ \\
Race/Ethnicity & \\
Non-Hispanic White & $3213(71.24)$ \\
Hispanic & $608(13.48)$ \\
Non-Hispanic African American & $222(4.92)$ \\
Other race/ethnicity combinations & $467(10.35)$ \\
\hline
\end{tabular}




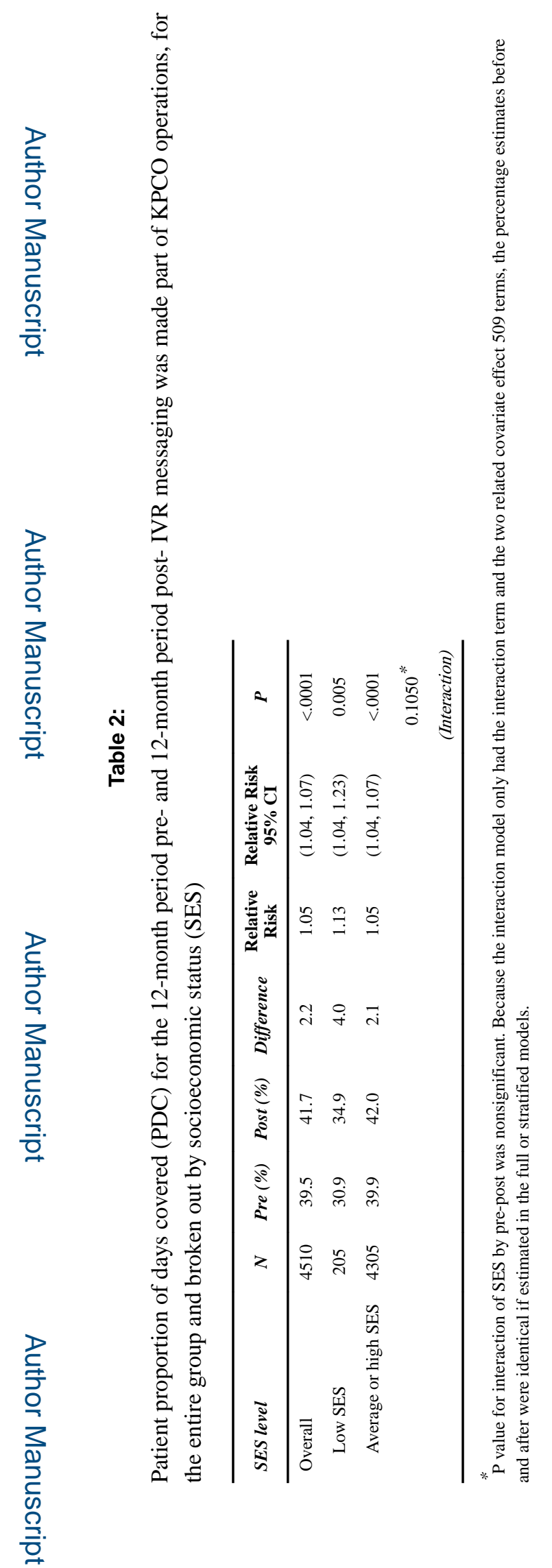

J Allergy Clin Immunol Pract. Author manuscript; available in PMC 2020 March 01. 
Table 3:

Exacerbation analysis for patients with persistent asthma, pre- and post-intervention $(\mathrm{N}=4510)$

\begin{tabular}{|c|c|c|c|c|c|c|}
\hline Exacerbation type & Pre (\%) & Post (\%) & Difference & $\begin{array}{l}\text { Relative } \\
\text { Risk }\end{array}$ & $\begin{array}{c}\text { Relative } \\
\text { Risk 95\% } \\
\text { CI }\end{array}$ & $P$ \\
\hline \multicolumn{7}{|l|}{ All exacerbations } \\
\hline Hospital & $1.3 \%$ & $1.1 \%$ & $-0.2 \%$ & 0.85 & $(0.36,1.99)$ & 0.7076 \\
\hline Emergency room & $3.3 \%$ & $2.9 \%$ & $-0.4 \%$ & 0.87 & $(0.59,1.28)$ & 0.4933 \\
\hline Urgent Care & $1.7 \%$ & $1.9 \%$ & $0.2 \%$ & 1.13 & $(0.83,1.56)$ & 0.4385 \\
\hline $\begin{array}{l}\text { Prednisone with asthma } \\
\text { diagnosis }\end{array}$ & $28.3 \%$ & $26.2 \%$ & $-2.1 \%$ & 0.93 & $(0.85,1.01)$ & 0.0806 \\
\hline \multicolumn{7}{|l|}{ Outliers excluded $^{a}$} \\
\hline Hospital & $1.1 \%$ & $0.9 \%$ & $-0.2 \%$ & 0.88 & $(0.34,2.27)$ & 0.7842 \\
\hline Emergency room & $3.1 \%$ & $2.4 \%$ & $-0.7 \%$ & 0.78 & $(0.52,1.18)$ & 0.2374 \\
\hline Urgent Care & $1.5 \%$ & $1.6 \%$ & $0.1 \%$ & 1.07 & $(0.77,1.5)$ & 0.6733 \\
\hline $\begin{array}{l}\text { Prednisone with asthma } \\
\text { diagnosis }\end{array}$ & $26.4 \%$ & $23.8 \%$ & $-2.6 \%$ & 0.90 & $(0.82,0.98)$ & 0.0212 \\
\hline
\end{tabular}

${ }^{a}$ Outliers were patients who experienced an exacerbation between August 23 and September 23 in both $\underline{2013}$ and 2014, when exacerbations were atypically high. 

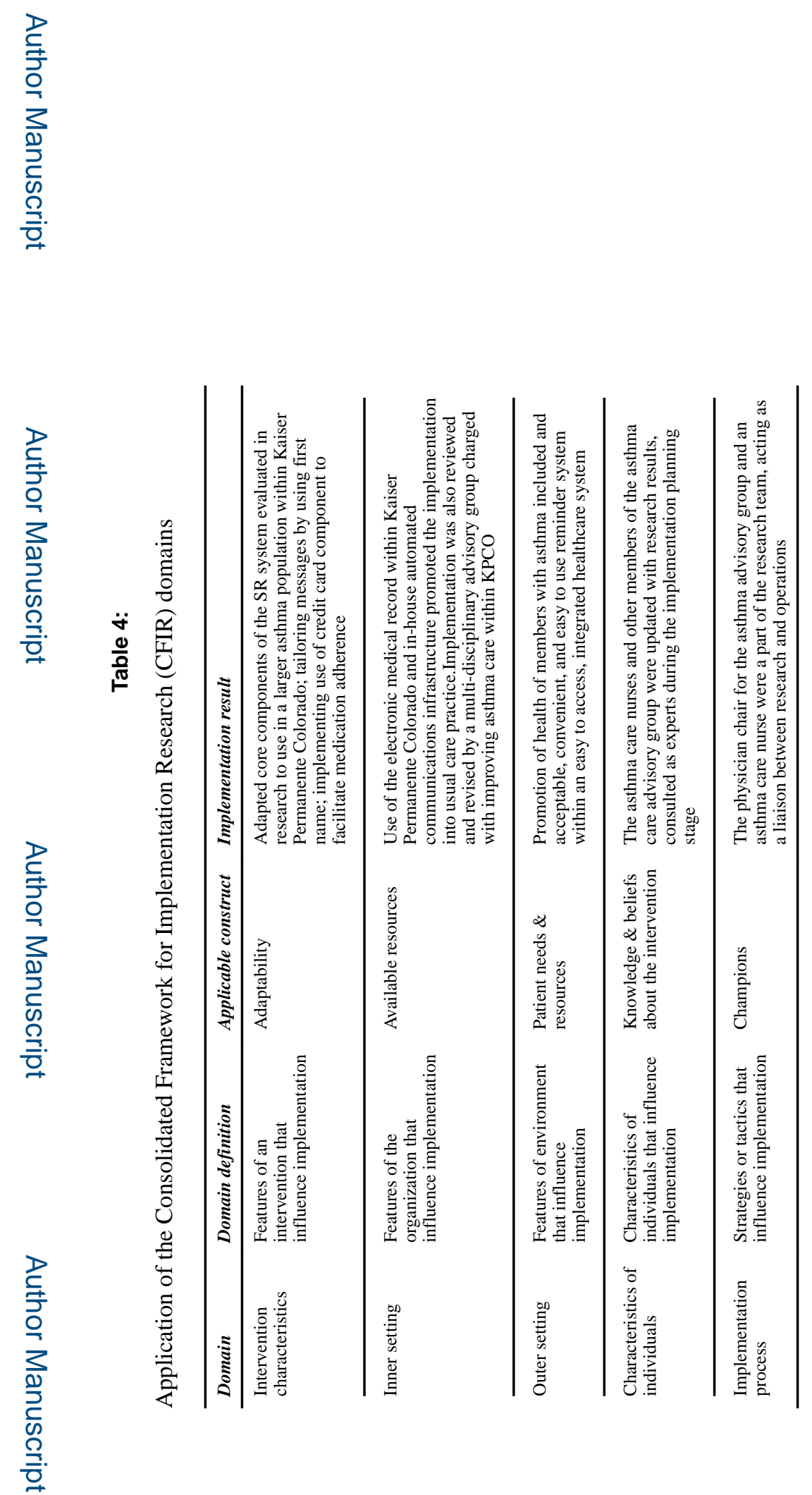

J Allergy Clin Immunol Pract. Author manuscript; available in PMC 2020 March 01. 